\title{
Os Aprendizes das Ruas e a Tríade Educação, Trabalho e Cidadania
}

\author{
Street-learning people and the \\ relationship among education, \\ work and citizenship
}

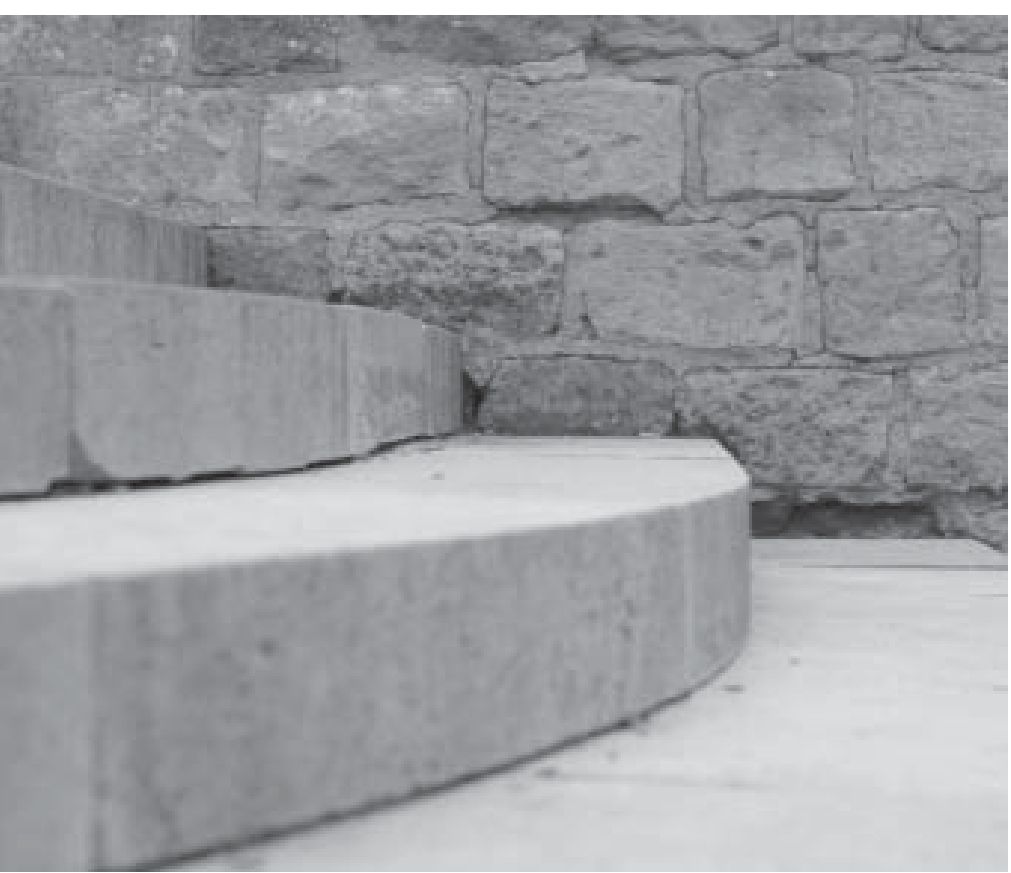




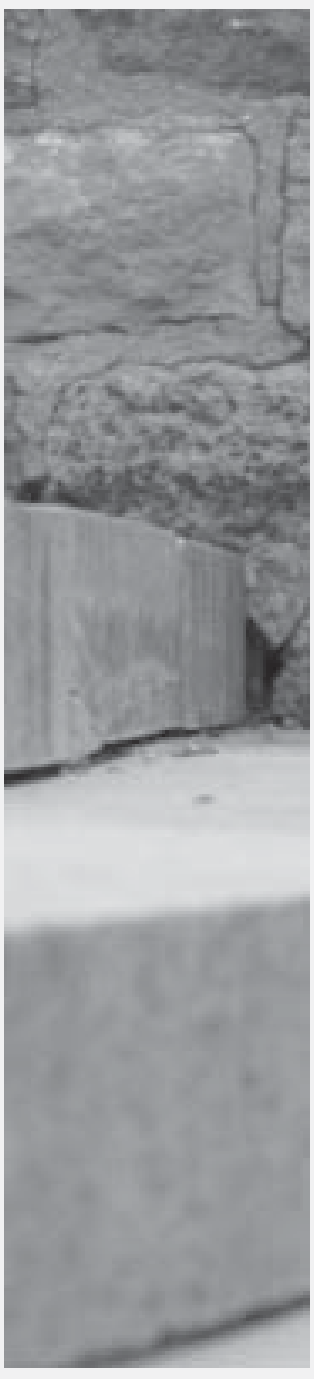

Resumo: Este estudo analisa a tríade educação, trabalho e cidadania, trazendo à cena a presença dos educadores de rua junto aos aprendizes das calçadas que, na década de 90 , retomam as ruas da cidade como local privilegiado de construção de suas existências. A partir da interferência de uma acepção de cidadania a ser produzida, novos sentidos vão-se constituindo com relação ao significado do trabalho na vida de meninos e meninas que circulam nas ruas da cidade. Nas ações empreendidas por esses educadores, a questão do trabalho como única saída para crianças e jovens empobrecidos perde a proeminência, tornando-se apenas uma das dimensões que a vida comporta. Diante dos aprendizes das ruas, buscamos dar visibilidade à multiplicidade de vínculos, variações e peculiaridades estabelecidas nos afazeres entre educadores e aprendizes: espaço de convivência, de socialização, do exercício do lúdico, da expansão de habilidades artísticas, entre outros, configurando-se em práticas educativas inovadoras.

Palavras-chave: trabalho, educação, cidadania, subjetividade.

Abstract: This article analyzes the relationship among education, work and citizenship highlighting the experience of street social education. The focus is the educative experience among educators and street-learning people during the 1990 decade. They build a new concept of citizenship and give a new meaning to work to boys and girls who live in the streets. These educators don't centralize their hope in the role of work to save children. For them, work is just one way to support those kids and young people. There are many opportunities to make their lives better: living together, socializing, playing games, developing artistic abilities. All these ways of learning make possible a new educative practice.

Key words: education, work, citizenship, subjectivity.

No convívio com crianças e jovens que vivem em situação de pobreza, uma preocupação insiste em rondar suas mentes e corpos de forma quase que unânime: ter uma ocupação ${ }^{1}$. O mais espantoso é que esse "ter que arranjar uma ocupação" encontra terreno fértil nas instituições em que transitam. Assim, nos abrigos, escolas e projetos, deparamo-nos com uma gama de técnicos, professores, administradores e familiares que conjugam a idéia de um destino quase inexorável para crianças e jovens empobrecidos, ou seja, como primeiro e, talvez, único projeto de vida inserir-se em qualquer atividade laborativa.

Essa idéia, de algum modo dominante, naturalizada no senso comum e nas práticas institucionais, reduz a infância e juventude pobre à perspectiva laboral. Embora, historicamente, tal perspectiva tenha causado a indignação de grupos, de pessoas, de importantes movimentos sociais e políticos, pouco alterou a orientação hegemônica em termos de projetos a médio e longo prazo que
10 uso da expressão 'ter uma ocupação', no lugar da palavra 'trabalho', implica uma apropriação da distinção proposta por Arendt (1995) entre labor e trabalho. A autora aponta, retomando a Antiguidade Clássica, o desprezo que os gregos nutriam pelo labor, haja vista que qualquer atividade que não fosse política era considerada subserviente. Sob essa $p$ ers $p$ e c t $i v a$. identificavam trabalho com escravidão, já que trabalhar implicava, sempre, encontrar-se em uma condição servil. Ao contrário, na Era Moderna, glorificou-se o trabalho como fonte de todos os valores, operando-se distinções, entre as quais: trabalho produtivo $e$ improdutivo, trabalho qualificado $e$ não qualificado, trabalho manual e intelectual. Queremos ressaltar, desse modo, que as expressões 'laborar' e ou "ter uma ocupação", usadas nesse artigo, atualizam a acepção grega de servilidade. 
É uma história do presente, expressa na perspectiva foucaultiana, que implica, também, uma outra inversão no caminho trilhado pela filosofia tradicional ou pela Psicologia daquilo que nomeiam como a questão do sujeito e da intersubjetividade

Deleuze consistam, de fato, em trazer outras respostas à seguinte questão: por que, para crianças e jovens pertencentes aos segmentos populares, a terapêutica apresentada é sempre o labor? De posse dessa primeira questão-problema, procuramos acompanhar e analisar alguns traços tecidos historicamente no encontro entre a problemática do trabalho e os jovens aprendizes a partir da especificidade brasileira, dando ênfase às diferentes perspectivas de ação daí derivadas.

Nesse desvio histórico, necessitou-se operar uma inversão de natureza temporal na forma de conceber o ato de historiar e compreender que "não é o passado que engendra o presente, senão que o passado está composto de uma série de potencialidades que o presente ativa, que o presente ilumina, que o presente deflagra" (Baremblitt, 1996, pp.41/ 43). É uma história do presente, expressa na perspectiva foucaultiana, que implica, também, uma outra inversão no caminho trilhado pela filosofia tradicional ou pela Psicologia daquilo que nomeiam como a questão do sujeito e da intersubjetividade (Deleuze, 1986).

Dentro da perspectiva aqui trabalhada, a subjetividade é concebida como produção, sendo composta de diversos elementos, seja de natureza interna e/ou externa (afetivos, familiares, do corpo, da mídia, da linguagem, do desejo, entre outros). Essa heterogeneidade de elementos, em constante processualidade, faz da subjetividade uma instância múltipla indissociável de práticas sociais concretas (Caiafa, 2000).

Interessados na concepção do pensamento enquanto experimentação, mais do que uma análise descritiva e fenomênica das questões suscitadas entre os aprendizes das ruas e a tríade educação, trabalho e cidadania, elegemos Foucault (1997) e a singularidade de um pensamento que atualiza uma idéia de existência sendo trabalhada na perspectiva estética, segundo o autor, já encontrável nos gregos, estética da existência como problematização de si ou uma prática de si num terreno ético.

Com o método foucaultiano, acessamos a atualização das formas de fabricação social e histórica da subjetividade aprendiz, as quais buscaram aprisionar a condição de aprendiz a uma configuração de vida medíocre, investindo na direção e produção de um ser impotente e submisso.

Analisando os modos de subjetivação dominantes, inerentes ao campo do trabalho na vida desses meninos e meninas, pudemos constatar a produção de linhas portadoras de uma visão normativa, nomeadas neste estudo de contínuas ou duras. Essa visão, situada dentro dos parâmetros de equilíbrio e conformidade ao meio, encontrou, nas práticas de trabalho, um dispositivo normatizador, que se plasmou na existência de crianças e jovens dos segmentos populares ou tidos como desviantes, reduzindo a multiplicidade de sentidos própria à dimensão e invenção de ser um "eterno aprendiz".

Embora as linhas contínuas ganhem maior visibilidade, insistimos na busca de outros traçados a partir dos quais a relação entre trabalho e jovens pobres possa escapar a níveis de intervenção normativos, produtores de uma perspectiva de vida que não reduza a condição de aprendiz a uma feição meramente laborativa. Finalmente, encontramos esboços dessas linhas no Brasil, particularmente nas décadas de 70, 80 e 90, as quais nomeamos de linhas descontínuas ou flexíveis.

Associamos essas linhas descontínuas ou flexíveis a uma nova forma de abordar a temática do trabalho, isso porque elas trazem uma outra mentalidade associada a uma nova vontade que altera os modos de pensar, sentir, viver e tratar o processo por meio do qual o jovem se torna um aprendiz no Brasil. 
Tais linhas trazem uma nova configuração na questão do trabalho quando, especialmente na década de 70 , tentam compor geração de renda e dar ênfase no desenvolvimento de um processo educativo junto aos jovens fora de um espaço de reclusão. Posteriormente, na década de 80, são linhas que produzem rupturas com as práticas especializadas das instituições e combatem a política de isolamento, negligência e reclusão, e, finalmente, na década de 90, são linhas que tentam escapar a um campo restrito de oposições expressas nas dicotomias trabalho $x$ vadiagem, trabalho $x$ educação, para a trilogia educação, trabalho e cidadania, por meio da qual se vislumbra uma vontade de mudar a atitude frente à questão do trabalho.

A importância de centrarmos nossa análise nas ações empreendidas, notadamente nas décadas de 80 e 90, e, ainda, destacando os aprendizes das ruas, é por compreendermos que suas intervenções introduziram um exercício singular de uma cidadania a ser produzida, trazendo, por conseguinte, formas inusitadas de conceber a relação corpo, aprendiz e trabalho.

São formas que combatem e expõem as condições desiguais que alicerçam a vida desses aprendizes. Nesse aspecto, busca-se abandonar concepções morais expressas na responsabilização das famílias e sua situação de pobreza como determinantes pelos desatinos de suas crianças e jovens, assim como movimentos e organizações da sociedade civil exigem providências diante dos abusos e descaso perpetrados contra o que ficou designado, nesse período, como meninos de rua.

Ao invés de meninos de rua, buscamos, em nossa análise, referenciar os aprendizes das ruas. Trata-se não apenas de uma mudança na nomenclatura, mas, fundamentalmente, de pensar o aprendiz como um experimentador de si, posto que estar na condição de aprendiz não é outra coisa senão produzir sentidos que coloquem em cheque as verdades dadas pelas significações dominantes.

Para tanto, retomamos os gregos e suas formas de confeccionar práticas que compreendiam a experiência aprendiz a partir das relações estabelecidas com a política, com a pedagogia e as inúmeras funções daí depreendidas: de crítica, de luta, curativa, terapêutica, entre outras.

Esse caráter múltiplo de conceber a condição de aprendiz, fundada nas práticas que os gregos chamaram "ocupar-se de si", traz, de modo concomitante, a força de pensar o aprendiz para além de significações ou representações prévias. Assim, o aprendiz experimentador de si será abordado como um ser precário, na medida em que não possui respostas ou atitudes já formadas para reagir a determinadas situações. É um aprendiz lançado em experimentações através das quais irá experimentar o que o torna aprendiz. Nesse lançamento, o aprendiz abre mão de fórmulas prontas, fazendo valer um aprendizado vivo, onde as soluções serão efeitos desse aprendizado, nunca as causas.

Tomando o aprendiz em seu sentido inacabado, provisório e indeterminado, situamos a sua condição adotando lentes que buscam, como campo de problematização, a composição cidadania e trabalho, composição que será tomada com um exercício problemático com o qual o aprendiz irá se defrontar, posto que é na ordem do encontro que o aprendizado se inicia. São confrontos que fazem, do aprendiz, um experimentador de si.

\section{Os aprendizes das ruas e a composição trabalho e cidadania}

Na história das iniciativas e, mais tardiamente, das políticas endereçadas à infância e
Esse caráter múltiplo de conceber a condição de aprendiz, fundada nas práticas que os gregos chamaram "ocupar-se de si", traz, de modo concomitante, a força de pensar o aprendiz para além de significações ou representações prévias. 
Nas sociedades artesanais, a condição de aprendiz correspondia à aquisição de conhecimentos e de experiência prática para iniciar-se na vida. juventude, a questão do trabalho, em diferentes conjunturas, adquiriu nuances, marcas e discursos diversos, abarcando componentes heterogêneos, produtores de inúmeras configurações.

Nas sociedades artesanais, a condição de aprendiz correspondia à aquisição de conhecimentos e de experiência prática para iniciar-se na vida. Nessa direção, o trabalho era concebido como uma das formas de sociabilidade dos modos de existência.

A partir de um longo processo de cisão da vida social, o trabalho deixa de apresentar-se como uma das dimensões da vida. Trata-se de uma cisão marcada, especialmente, por abalos nas formas de organização do trabalho, provocados, em parte, pelo capitalismo mercantil e pela gestão social da pobreza, transformando a condição de aprendiz num campo de enfrentamento e embate, já que o trabalho passa a trazer um caráter coercitivo, o que diminui seu sentido formativo.

O caráter coercitivo estava presente no trabalho reservado àqueles que exerciam as artes mecânicas, os ofícios, o trabalho manual, o trabalhado da terra. Embora o aspecto coercitivo contrarie, em certa medida, o estabelecimento de uma mão-de-obra livre, ele promove, concomitantemente, um ordenamento social que abrange tanto os que se incluem no sistema de ofícios como os que estão fora de tal sistema.

Os que se enquadram no idioma corporativista ganham uma condição de ser, que significa o acesso a uma existência revestida de um certo status social, mas nem por isso escapam do modo coercitivo impresso em suas regulamentações. Aos que não puderam conservar ou mesmo conquistar um lugar na ordem social, considerando as condições de trabalho vigentes, resta-lhes o trabalho forçado. Em ambas as modalidades, instituem, no campo do trabalho, o paradigma da coerção ou da obrigação.
Com o advento da sociedade industrial, a condição de aprendiz retoma, paulatinamente, seu sentido de formação. Entretanto, tal formação já não se estende por toda a vida, como nas sociedades artesanais, mas restringese a uma espécie de moratória que implica uma sociabilidade capaz de renunciar, temporariamente, à necessidade, no caso do jovem, de garantir o seu sustento. No entanto, tal formação tornou-se um privilégio de jovens burgueses, restando ao aprendiz pertencente aos segmentos empobrecidos da população uma cultura de contrapor a escola e seu processo formativo à vida de trabalho.

No Brasil, particularmente a partir da década de 30 , as idéias e concepções de trabalho apresentavam-se em contraposição à vadiagem, para, em seguida, o trabalho ser problematizado em oposição à educação. Mais recentemente, a formação da trilogia educação, trabalho e cidadania, defendida na década de 80 por amplos setores da sociedade organizada e presente no texto legal do Estatuto da Criança e do Adolescente, passa a ganhar ênfase nos trabalhos desenvolvidos pelas ONGs, principalmente aquelas nascidas na linha da promoção da cidadania de sujeitos sociais emergentes. Ainda dentro dessa acepção cidadã, com relação à condição de aprendiz, crescem as iniciativas pautadas na urgência de contraposição ao trabalho infantil, assim como incentivam uma política de proteção e profissionalização.

Mais recentemente, essas iniciativas vêm sendo desenvolvidas pelo governo brasileiro e por organizações de cooperação internacional, como a Unicef e as organizações não governamentais (sindicatos, fundações privadas). A partir de 1997, o programa Brasil Criança Cidadã, do Ministério da Previdência e Assistência Social, passou a conceder uma bolsa de $\mathrm{R} \$ 50,00$ por criança retirada do trabalho e encaminhada à escola. O programa foi implantado em vários Municípios e beneficiou inúmeras crianças. No entanto, 
apesar de o modelo inovar em termos de ações integradas entre os governos federal, estadual e municipal, ele peca quando institucionaliza ações de natureza emergencial, tornando-as soluções definitivas para problemas que demandam políticas de longo prazo. Hoje, muitos dos adolescentes que participaram do programa tiveram que retornar ao convívio com a exploração do trabalho, dada a situação de desemprego no País (Rizzini,1999).

Na década de 90, particularmente, a temática do trabalho sofrerá a interferência de mais um elemento, a saber, a cidadania. Essa composição entre trabalho e cidadania será tecida com uma parcela de aprendizes que tomam a rua como espaço de circulação, buscando, nesse trânsito, formas de convivência e sobrevivência.

Referimo-nos a apenas uma parcela de crianças e jovens nas ruas, isso porque, desde a década de 70, os sistemas oficiais de estatísticas, referendados em parâmetros generalizantes, contabilizavam o que se convencionou chamar "meninos de rua". Tais crianças e jovens eram vistos, por esses sistemas e pelo senso comum, dentro de uma tendência que associava carência material à ausência de proteção familiar e, não raras vezes, à adoção de condutas delinqüentes. Por conseguinte, considerando tal tendência, o número de crianças nas ruas situava-se ora aos milhares, ora aos milhões. De acordo com Gregori (2000), a primeira contagem foi realizada na cidade do Rio de Janeiro, pelo Ibase. Nessa contagem, foram utilizados dados relativos a crianças de rua e às respectivas mães, atendidas por entidades, quando se apurou, na ocasião, "a existência de 1255 crianças e adolescentes nos logradouros públicos até as 23 horas e 695 às 4 horas da manhã" (Gregori, 2000).

O que é importante ressaltar é que as ações voltadas para os ditos "meninos de rua" centraram-se, basicamente, na compreensão da dinâmica de sociabilidade que esses aprendizes instauram na convivência que estabelecem com as ruas. Desse modo, assistimos ao nascimento de formas singulares de intervenção que tentaremos compreender à luz da conjugação trabalho e cidadania.

\section{Os aprendizes ocupam as ruas}

A questão da cidadania, até então ausente nas ações e intervenções junto a crianças e jovens pobres que buscam as ruas como território de sobrevivência, parece arejar as práticas dirigidas a esses aprendizes. Através, prioritariamente, dos trabalhos desenvolvidos pelas ONGs, inaugura-se um precioso postulado ético, expresso no seguinte pressuposto: não podemos e nem devemos desistir dos meninos aparentemente desgarrados de nossas ruas.

A vitalidade dessas intervenções consistiu no trabalho realizado por cada educador, no que concerne, em particular, a sua "contrapresença" na rua em meio a uma sociedade que se mostrava hostil ao menino, uma contrapresença portadora do desejo, da parte sã da sociedade, de restaurar seus laços com o menino. Esse desejo implicava, para o educador, num primeiro momento, estar desarmado, inclusive de método e teoria, o que consistiu em buscar aquilo que pudesse emergir da maturação do encontro (Milito \& Silva, 1995).

Mesmo considerando todas as adversidades e dificuldades de sistematização dessas experiências - compreendidas nesse período como, fundamentalmente, precariedade teórica e inadequação das calçadas como local para o exercício da educação -, estar nas ruas junto aos aprendizes significou recusar os modelos de ação vigentes, até então restritos a recolher crianças e jovens das ruas ou retirálas do convívio com suas famílias, diagnosticadas, de maneira geral, como desestruturadas, restando, como prática social de intervenção, o confinamento em instituições para esse grupo específico.

Buscou-se "cuidar do problema onde ele aparece - na rua" - à vista de todos, dando 


\section{"(...) de renúncia em favor da segurança que atravessa a produção do princípio de Estado, a idéia de consentimento em favor da preservação da propriedade que engendra a produção do princípio de mercado e a idéia de vontade geral que sustenta o princípio de comunidade.}

maior visibilidade ao esfacelamento social que irradiava através da proliferação de crianças e jovens nesses espaços e o que essa presença massiva denunciava na sua ambigüidade. Tal ambigüidade se traduz na constatação das “condições deploráveis e desumanas em que vivem ou na irritada propensão a considerálos deploráveis e desumanos por condição" (Milito \& Silva, 1993, p.95).

Nos interstícios dessa ambigüidade é que constatamos o quanto esses trabalhadores sociais, operando em "locais de pouco ou nenhum controle", acolheram, na medida em que lhes foi possível, modos de vida que escapavam - ou mesmo resistiam - aos esquemas de modelização em vigor, tomandoos no seu avesso. Nesse avesso, interessava, enquanto matéria de problematização, o que nesses aprendizes se esgarçava ao tecerem suas errâncias nas ruas da cidade, em termos do que lhes é de direito viver, entendido esse direito para além de uma "matriz cidadã", já que não se tratava apenas de:

“(...) denunciar aqueles que não possuem "A Cidadania", muito menos apelar para um princípio cidadão que viesse, finalmente, alinhavar as variedades de cidadania encontradas no tecido social brasileiro. Mas antes...o de como forjar dispositivos capazes de neutralizar as forças que dão sustentação à "Vontade-de-Cidadania" que tem prevalecido no Brasil, prisioneira de ideais de significação dominantes, materializados, historicamente, sob a forma de procedimentos de submissão, tutela ou obstrução da capacidade de reação do corpo social" (Fonseca, 1997, p.94).

Tendo como dispositivo uma pedagogia das calçadas a partir de uma contrapresença dos educadores de rua, ultrapassou-se, nessas intervenções, a dicotomia cidadania consentida x cidadania conquistada para um caminho às avessas de uma cidadania produzida.
A noção de cidadania produzida refere-se, de acordo com Fonseca (1997), a um exercício analítico que visa pôr em análise sentidos e valores construídos por um ideário europeu, onde ser cidadão implica, necessariamente, um direito inquestionável, "restando-nos somente ou os esforços para sua aquisição ou o ressarcimento por não tê-lo adquirido", isso porque a noção de cidadania correspondente a tal ideário é sustentada pela idéia:

“(...) de renúncia em favor da segurança que atravessa a produção do princípio de Estado, a idéia de consentimento em favor da preservação da propriedade que engendra a produção do princípio de mercado e a idéia de vontade geral que sustenta o princípio de comunidade. Tais princípios heterogêneos e complementares puderam consolidar a distinção Estado-sociedade reatando, ao mesmo tempo, suas ligações através da idéia liberal de contrato social" (Fonseca, 1997, p. 03).

No caso do aprendiz que se encontra nas ruas, qual a natureza da idéia de renúncia quando sua segurança se encontra abalada nos espaços liminares que transita? Consentir a favor de que espécie de propriedade, se sua existência denuncia um processo de desapropriação histórica, restando-Ihe conviver e suportar um mercado que o coloca na condição de miserável e despossuído? Por fim, o que significa submeter-se à vontade geral de uma "comunidade" que, dominantemente, comunga com um regime de evitação, repressão e extermínio?

Tais princípios são embaralhados e geridos por uma condição e um corpo aprendiz que, em seu nomadismo, a partir de rumos e apropriações diferenciadas, acusa, diverge, recusa, desconecta, torna-se alheio às crenças que portam "o cidadão" e seus respectivos valores, ou seja: "identidade, privacidade, liberdade, autonomia para gerir seus bens, igualdade e felicidade" (Fonseca, 1997). 
Na produção de uma cidadania às avessas, mais do que acolher e educar esses aprendizes, tais experiências passam a privilegiar a vida enquanto processo, tendo como instrumento privilegiado o próprio corpo do aprendiz e o que dele deriva na sua ligação com as dimensões do tempo, com o plano das fantasias, de modo a favorecer o exercício lúdico, o senso de pertença e desejo, fazendo derivar linhas singulares.

O que nos parece fundamental extrair desses trabalhos junto aos aprendizes que circulam nas ruas é a capacidade de se gestarem intervenções que conseguiram distrair, para elas mesmas, a forma como essas crianças e jovens são comumente tratados, ou seja, os portadores da "expressão emblemática da miséria, da vulnerabilidade e da violência". Para tanto, a pedagogia das calçadas distanciouse de referenciais que os concebem, unicamente, sob o ponto de vista da carência e da falta.

Ao contrário, vistos por aquilo que eles podem ser, mais do que sobre sua história pregressa ou ainda pelas possíveis causas que os levam a abandonar o convívio com seus familiares, não desqualificando a importância de questões nesse âmbito, essas intervenções puderam ser somadas ao que se estava processando naqueles modos circulantes de vida, ampliando inclusive o sentido de estar nas ruas:

“(...) A rua é um termo genérico demais: a vivência dos meninos me ensinou que esse espaço - hoje, mais que antigamente - é composto por um conjunto de ações apoiadoras de natureza das mais diversas (individuais, institucionais governamentais e não governamentais) e que permitem a conquista de bens não só materiais - como se servissem, apenas, à sobrevivência puramente física - mas também simbólicos e identitários. E porque existe essa "acolhida", percebi como os diferentes agrupamentos de meninos de rua têm apreço por uma determinada territorialidade, fixando-se com maior ou menor intensidade, dependendo de como se inscrevem no interior de uma dinâmica local (Gregori, 2000, pp. 56/57),

Nessa "viração", o aprendiz vai sendo nomeado, tratado e objetivado como menino de rua, tomado a partir de inúmeras posições e imagens que, por vez, instituem lugares sociais que serão apropriados por esses aprendizes. Vemos, desse modo, que os aprendizes vão construindo uma idéia de si mesmos, no encontro com o conjunto das ações que os apóiam, extraindo, nesse jogo mútuo, "um lugar e um benefício" (Gregori, 2000, p.58).

Nesse aspecto, o lugar do trabalho, para os projetos que tinham como campo de intervenção crianças e jovens que transitavam nas ruas, passa a ser conceituado sobre novas bases, tendo como reflexão a necessidade de composição entre ação educacional e promoção da cidadania, em que a profissionalização ganha forte expressão. No entanto, a questão da profissionalização passa a ser abordada em outros termos, já que o trabalho será compreendido como aquele que deve intermediar a ação pedagógica, onde a formação, através do processo de escolarização, assume papel fundamental.

Apesar de a profissionalização rondar o horizonte dessas iniciativas, um traço importante, que marca uma diferenciação na forma em que, historicamente, costumava ser tratada a relação juventude pobre e trabalho, é que este último perde a sua proeminência, dando lugar à entrada de intervenções mais centradas em outros aspectos e níveis da vida de crianças e jovens. Essas intervenções são dirigidas à construção da identidade pessoal, social e cultural do grupo em questão, já que o fato de estar nas ruas impõe interrogar sobre o tempo, a lógica e os significados dessas ocupações (Milito \& Silva, 1995).

Sob um determinado ângulo, transitar com os aprendizes nas ruas a partir da confecção coletiva de uma pedagogia das calçadas 
promoveu práticas que os retiraram do anonimato, exibindo e acirrando os percalços de uma sociedade que gesta, cotidianamente, a inutilidade, a decadência e a miséria de crianças e jovens tratados como "filhos de ninguém", uma denominação utilizada por Ribeiro (1995), que se refere ao processo de formação dos primeiros brasileiros a partir de uma diversidade composta por povos estranhos uns aos outros: o branco europeu, o negro e o índio".

No caso, o índio tornou-se um estranho em sua própria terra, visto que se viu transfigurado em uma nova etnia. Essa nova etnia, formada de brasilíndios ou mamelucos, sentia-se estranha com relação às suas matrizes étnicas e sofria de duas rejeições terríveis: a dos pais, que os viam como filhos impuros, e a do gentio materno, já que, na visão do índio, a mulher é apenas um depósito da semente do homem. Portanto, quem nasce é filho do pai. Assim, tornamo-nos brasileiros a partir dessa orfandade generalizada (Ribeiro, 1995).

No entanto, paralelamente, a adoção desses filhos teve que sobreviver e coexistir com uma espécie de subcultura de evitação, cuja visão de mundo traz, como seus ingredientes, a repressão, o extermínio, a chacina, o linchamento, a tortura policial praticada nas calçadas, "ração diária e tradicional temperada pelo medo e o sadismo, alguns deles ( como o jornal que, "se espremer, sai sangue") elementos tradicionais da cultura carioca" (Milito \& Silva, 1995, p. 33)

Nesse solo íngreme e na tentativa de se promover uma pedagogia das calçadas, emergem, como campo de forças, sentidos e valores obedientes aos princípios dessa cultura de evitação, colocando educadores e aprendizes vulneráveis quanto aos destinos e desatinos desse encontro. Esses desatinos passam a ser avaliados considerando em que medida os trabalhos realizados nos espaços das ruas permitem produzir novos agenciamentos, posto que, nelas, o amparo do conhecido é muito imperceptível, forjando aos aprendizes o desempenho de personagens para os quais nunca alguém escreveu texto algum.

No rascunho de pequenos textos, entre fragmentos incompletos de inumeráveis começos atravessados por intolerâncias e desafetos, cumplicidades e alianças, alguns deslocamentos foram operados, já que, se, por um lado, estar nas ruas travestiu crianças e jovens como seres livres e responsáveis pelos seus destinos, por outro, essas mesmas vestes e a suposta autonomia que portavam os tornava extremamente vulneráveis.

Os aprendizes, investidos desse novo estatuto - ser autônomo - lograram a responsabilidade por suas errâncias no mundo, ficando subtraídos os processos que engendraram o estilhaçar de uma infância e juventude e sua natureza incompleta, disruptiva e imprevisível.

Como devolver aos aprendizes das ruas e nas ruas o caráter de incompletude e provisoriedade que habita qualquer forma de existência?

Desdobradas em outras interrogações, novas perguntas foram sendo construídas nesse trajeto, principalmente na década de 90 e nos trágicos acontecimentos sucedidos durante o período, posto que, além da chacina da Candelária, em agosto de 1993, assistimos no mesmo mês, na periferia da cidade do Rio de Janeiro, à chacina de Vigário Geral. Esses acontecimentos fizeram com que os projetos dirigidos a esses aprendizes apressassem o processo pelo qual se deve tornar obsoleta a indagação perplexa - "o que ele quer" - pela instauração da pergunta-projeto - "o que queremos dele" (Milito \& Silva, 1995, p.166). Essa pergunta-projeto portou uma função estratégica, porque sustentada e articulada com as lutas sociais mais amplas, especialmente aquelas destinadas a tornar os princípios que regem o Estatuto da Criança e do Adolescente e sua doutrina de proteção 
integral em práticas efetivas junto a essa população específica. Em seu texto legal, estão contemplados novos conteúdos, métodos e formas de gerir as políticas públicas para a infância e juventude no País, norteados por três avanços importantes, ou seja, considerar crianças e adolescentes como sujeitos de direitos, pessoas em condição peculiar de desenvolvimento e prioridade absoluta.

Tendo o texto legal como pano de fundo e sofrendo a intercessão desestabilizadora de uma cidadania que foi sendo produzida no engajamento com crianças e jovens circundantes das ruas da cidade, novas verdades foram criadas no domínio do trabalho. Isso implica afirmar que, no domínio do trabalho, "nomadizaram-se", em certa medida, as fronteiras entre uma sociedade sã e os meninos "errantes" das ruas. Essas margens tornaram-se caóticas no encontro entre um corpo de intervenções dirigidas ao aprendiz, através de componentes múltiplos (gestos, afetos, presença, instituições, pedagogias, entre outros), perturbando os modos de subjetivação dominantes no campo do trabalho.

Com relação às formas de trabalho, elas passam a ser veiculadas na sua composição com ações que primaram em problematizar seu histórico caráter coercitivo, segregador e precário, quando se trata de uma infância e juventude pobres. O trabalho perde, parcialmente, para as ações voltadas para os aprendizes das ruas, o caráter de centralidade, tomando a cena outras referências que passam a privilegiar a formação, o lazer, os estudos. Nessas ações, está presente a aposta na invenção de um aprendiz problematizador de si mesmo, ávido na produção de sentidos que coloquem em análise as significações dominantes tornadas eternas quando no seu encontro com o trabalho, e, ao produzir sentidos que, do mesmo modo, o coloquem na disposição de criar, o aprendiz estará construindo mundos por vir.
Entretanto, tal disposição somente se realiza por meio de agenciamentos concretos operados por experimentações sociais que tenham a capacidade de travar uma "briga encarniçada contra a pobreza de opções disponíveis no mercado da vida" (Pelbart, 1993).

Identificamos essa briga nas práticas experimentadas pelo educador de rua junto aos meninos e meninas que circulavam nas ruas da cidade, práticas que evidenciaram forças às avessas do equilíbrio, contrárias ao senso adaptativo e às idéias verdadeiras que rondam o campo do trabalho em seu modo de produção dominante. Tais forças portaram a qualidade do novo, própria de todo começo, e criaram um outro plano de sustentação para os aprendizes das ruas.

\section{Conclusão}

Dando ênfase à composição educação, trabalho e cidadania, vimos multiplicar, na década de 90, programas cujas práticas se voltam para a construção de projetos próprios de vida que instaurem, para o aprendiz, uma outra maneira de estabelecer vínculos com uma sociedade que comumente o exclui.

Embora, para essas intervenções, o tema da profissionalização atravesse, de forma cada vez mais enfática, seus projetos conseguem, num primeiro momento, abordá-la, primando antes pelo processo de formação do aprendiz, o qual exalta especialmente a criação de uma experimentação estética. Tal experimentação passa a ser conduzida por uma inquietação em relação às formas até então acionadas na tríade educação, trabalho e meninos e meninas que circulam nas ruas. Buscam-se, nas intervenções junto ao aprendiz, práticas mais interativas em que ele participe ativamente daquilo que o afeta, de modo a confeccionar um plano de consistência para vidas que herdam um processo histórico de vulnerabilidades de todas as ordens. Essas práticas são referendadas em uma cidadania a ser constantemente produzida.
Tendo o texto legal como pano de fundo e sofrendo a intercessão desestabilizadora de uma cidadania que foi sendo produzidano engajamento com crianças e jovens circundantes das ruas da cidade, novas verdades foram criadas no domínio do trabalho. 
Se, às crianças e aos jovens pobres, foi destinada, quase dominantemente, uma perspectiva de projeto de vida ancorada no trabalho, vimos, em contrapartida, no decorrer dos anos 80 e especialmente na década de 90, linhas que apontam descontinuidades na história das iniciativas voltadas para a tríade educação, trabalho e crianças e jovens pobres no País. Naquele contexto, argumentou-se mais veementemente a favor da vida de crianças e jovens que acumulam uma condição histórica circunscrita à realidade do trabalho precoce e precário, do abandono e da negligência.

Ao revisitarmos quem se ocupa, atualmente, de modo dominante de meninos e meninas em situação de pobreza e, dentre estes, os que circulam nas ruas, vemos uma infinidade de projetos, programas e propostas promotores de experiências que englobam trabalhos portadores de naturezas e valores distintos: comunitárias e de solidariedade; voluntaristas e filantrópicas; elitistas e assistencialistas; de justiça social e de participação cidadã; empresarial e mercadológica.

Esses diferentes projetos, idéias, instituições e práticas prescrevem, nomeiam e designam lugares sociais, circunscrevendo o aprendiz entre uma direção mais privatista, ligada à esfera da produção, e outra dentro de um caráter público atrelada à esfera do Estado.

Não obstante, a limitação de um campo de experimentação junto à esfera do mercado e ou à esfera do Estado corre o risco de aprisionálo num processo circular, formando, desse modo, uma verdadeira trama para os meninos e meninas que circulam nas ruas. Segundo Gregori, essa trama acaba por alimentar a própria circulação, já que são inúmeras as mudanças de curso que sofrem as políticas de atendimento. Acrescem-se, ainda, fatores que "vão desde a competição por recursos, passando pela rivalidade política, até o desconhecimento das novas regras do jogo que toda nova configuração implica". Desse modo, "o estímulo a circular e a se virar se intensifica, na experiência diária de adotar uma posição que traga benefícios segundo cada tipo de prática adotada" (Gregori, 2000, p. 58).

Nessa circulação e viração, práticas efetivas vão sendo conduzidas e dirigidas ao aprendiz e das quais ele tenta apropriar-se, estabelecendo vínculos de natureza diversa. Daí a vital importância de compreender a natureza desses vínculos, de modo que possam ser recompostos e abalizados, tendo como eixo norteador um conjunto de valores éticopolíticos e estéticos, que articulem a problemática social à existencial, de modo que haja um enriquecimento mútuo entre seus componentes.

Para tanto, é preciso considerar os níveis macropolíticos que as práticas sociais engendram quando buscam recompor as lutas democráticas, as forças políticas e sociais em jogo, mas, igualmente, os de ordem da micropolítica que se dirigem a uma reapropriação da vida social e subjetiva, isso porque é sob o domínio dos processos de produção de subjetividade que o capitalismo expande, de modo cada vez mais impetuoso, suas fronteiras.

Como assevera Guattari (1987), há um tipo de democracia da vida cotidiana que convém, continuamente, inventar e que reverbera no sentido do dissenso, ou seja, no sentido de produzir processos de singularização que inventam um novo tipo de subjetividade.

Essa invenção, apreciada por uma perspectiva que toma o aprendiz como um experimentador de si, somente será gestada na produção de sentidos que não se rendam às significações dominantes e que busquem, ininterruptamente, submetê-lo a valores estabelecidos. 


\section{Silvana Mendes Lima}

Doutora em Ciências na área de Saúde Pública da Fundação Oswaldo Cruz.

Professora assistente do Centro Universitário Celso Lisboa.

Rua Desembargador Itabaiana de Oliveira,

24/402 - Icaraí - Niterói-RJ Cep:24230-135.

E:mail:mendes-lima@uol.com.br

Recebido 23/11/04 Reformulado 23/08/05 Aprovado 07/03/06

ARENDT, H. A Condição Humana. Rio de Janeiro:Forense Universitária, 1995.

BAREMBLITT, G. Compendio de Análise Institucional e outras Correntes: Teoria e Prática. Rio de Janeiro. Editora Rosa dos Ventos, 1996.

CAIAFA, J.Nosso Século XXI: Notas sobre Arte, Técnica e Poderes. Rio de Janeiro: Editora Relume-Dumará, 2000.

DELEUZE \& GUATTARI, F. Mil Platôs: Capitalismo e Esquizofrenia, vol. 3. Rio de Janeiro: Editora 34, 1996.

FONSECA, D.F. Avessos da Cidadania: um Exercício Analítico Dissertação de Mestrado, São Paulo: PUC,1997.

FOUCAULT. M. Resumo dos Cursos do Collège de France (19701982). Rio de Janeiro: Jorge Zahar Editor, 1997.

GREGORI, M.F. Viração - Experiências de Meninos nas Ruas. São Paulo: Cia das Letras, 2000.
GUATTARI, F. \& ROLNIK. S. Micropolítica: Cartografia do Desejo. Petrópolis: Vozes, 1986.

MILITO C.\& SILVA H.R.S. Vozes do Meio-Fio. Rio de Janeiro: RelumeDumará, 1995.

PELBART, P.P. A Nau do Tempo Rei: 7 Ensaios sobre o Tempo da Loucura. Rio de Janeiro: Imago Editora, 1993.

RIBEIRO, D. O Povo Brasileiro - a Formação e o Sentido do Brasil. São Paulo: Companhia das Letras, 1995

RIZZINI, I. Pequenos Trabalhadores do Brasil. In: História das Crianças no Brasil (M.Del Priore, org.). São Paulo: Editora Contexto, 1999, pp.376-406.

Lei

BRASIL, Lei n. 8069, de 13 de julho de 1990. Estatuto da Criança e do Adolescente. Rio de Janeiro: CEDCA, 1998. 